\title{
Serious soccer, sex (work) and HIV - will South Africa be too hot to handle during the 2010 World Cup?
}

Soccer fever is sweeping through South African streets - be they tarred, dusty or potholed. Stadiums are being polished until they shine, road signs repainted, and dank garden sheds converted into pricy bed \& breakfasts. South Africa is putting its best foot forward, and wherever panic rears its head the FIFA Local Organising Committee and politicians are doing damage control.

Yet a troubling and neglected topic is sex. Indeed, with the expected influx of visitors, more sex. If the AIDS epidemic has taught us anything, it is that sex is a part of human behaviour that neither governments nor the law can control. Newspaper reports have alluded to the fact that South Africa has one of the highest HIV prevalence rates in the world and that 'innocent' tourists might return home with nasty HIV from Africa. ${ }^{1-3}$ Worse still, that these 'innocent' tourists will consort with 'dubious' sex workers and find themselves languishing in overcrowded South African prisons ${ }^{4}$ long after the last vuvuzela has announced the end of the final game. Indeed, Dutch soccer fans have been warned to bring their own condoms, as South Africa might run out, ${ }^{5}$ the Department of Health has responded by assuring everyone that it is well prepared. ${ }^{6}$ Recently, Britain donated a million pounds for an additional 42 million male condoms. ${ }^{7}$

Is this all hype? There is no systematic research showing a dramatic increase in the demand for paid sex during international sporting events. Before the last World Cup, in 2006, over-heated media reports suggested that 40000 women and children would be trafficked into Germany to meet the demand for paid sex of three million soccer tourists. ${ }^{8}$ Only five people were subsequently found to have been trafficked during that period. ${ }^{9,10}$ Hypotheses offered for the low interest in (paid) sex were that the World Cup was not particularly a 'male event', because families attended, many low-budget tourists had money only for tickets and transport, and even that the hot weather might have reduced sexual drive. ${ }^{10}$ Studies are currently underway to evaluate demand and supply of paid sex and adult entertainment during the South African World Cup - will the wintry but scorching African sun play a role?

Notably, Germany legalised sex work in 2002 - partly in anticipation of its hosting of the World Cup in 2006. South Africa has not been as quick on the uptake. The South African Law Reform Commission has been considering changes to South Africa's criminal law on sex work for the last decade, but no recommendations have yet been made. ${ }^{11-13}$ Currently South Africa criminalises all aspects of sex work. A number of human rights, women's groups and AIDS organisations advocate that decriminalisation will have important public health benefits: expanding sex worker access to health, legal and social services, reducing unsafe working conditions, diminishing stigma, and empowering sex workers to negotiate safer sex..$^{14}$ The last recorded HIV prevalence rates among sex workers in South Africa were $45-69 \% .15,16$ This makes it difficult to dispute that sex workers need focused attention, care, resources and treatment - not scorn or disinterest. ${ }^{17}$ Other arguments urge that decriminalisation will be in accord with South Africa's commitment to human rights. ${ }^{13,18}$

Yet despite the hype and calls for reform, government so far has no official plan for sex work over the World Cup period. In an attempt to address this oversight, the South African National AIDS Council (SANAC) and the Sex Worker Education and Advocacy Taskforce (SWEAT) arranged a 2-day consultation in November 2009 for government, civil society and the media to debate strategies and approaches. The meeting recommended public health campaigns that target potential clients with education and condoms as well as the setting up 'sex worker-safe' clinics, a moratorium on sex workrelated arrests during the World Cup, and ongoing engagement of FIFA. ${ }^{19}$ Implementation of these recommendations is progressing at a snail's pace - reflecting the difficulties many feel about sex worker health and human rights.

The 100-day mark before kick-off has passed. The World Cup-generated interest in sex work should be welcomed and strategically utilised to mobilise resources, political will and law reform towards an under-served population. This would be an important legacy that will invest in public health.

\author{
Marlise Richter \\ International Centre for Reproductive Health \\ Department of Department of Obstetrics and Gynaecology \\ Ghent University, and \\ Visiting Researcher: Forced Migration Studies Programme \\ University of the Witwatersrand \\ Johannesburg
}

\section{Dianne Massawe}

Sex Worker Education and Advocacy Taskforce Cape Town

Corresponding author: M Richter (marlise.richter@gmail.com)

\footnotetext{
1. Bird R, Donaldson R. 'Sex, sun, soccer': Stakeholder-opinions on the sex industry in Cape Town in anticipation of the 2010 FIFA Soccer World Cup. Urban Forum 2009; 20: 33-46.

2009.

3. Ridge S. Killer at the World Cup - England fans risk HIV vice threat in South Africa. News of the World 13 December 2009

4. SAPA. Overcrowding a problem in SA prisons. Mail \& Guardian 9 July 2008.

5. Ramphekwa H. Bring your own condoms, Dutch fans urged. The Mercury 18 November 2009.

6. National Ministry of Health. Condom distribution during the world cup. 4 January 2010.

National Ministry of Health. Condom distribution during the world cup. 4 .
http://www.doh.gov.za/docs/pr/pro104-f.html (accessed 10 March 2010).

http://www.doh.gov.za/docs/pr/pr0104-f.html (accessed 10 March 2010).
. BBC. UK gives South Africa millions of condoms. BBC News, 9 March 2010.

8. Loewenberg S. Fears of world cup sex trafficking boom unfounded. Lancet 2006; 368: 105-106.

9. Germany Federal Criminal Investigation Office. Bundeskriminalamt. Bundeslagebild Menschenhandel 2006 Pressefreie Kurzfassung, August 2007. http://www.bka.de/ lageberichte/mh/2006/mh2006.pdf (accessed 10 March 2010).

10. Hennig J, Craggs S, Larsson F, Laczko F. Trafficking in human beings and the 2006 World Cup in Germany. In: International Organization for Migration, ed. IOM Migration Research Series. Geneva, 2007.

11. South African Law Reform Commission. Sexual Offences: Adult Prostitution. Pretoria: South African Law Reform Commission, 12 July 2002.

12. South African Law Reform Commission. Discussion Paper 0001/2009. Pretoria: South African Law Reform Commission, May 2009.

13. Bodin C, Richter M. Adult, consensual sex work in South Africa - The cautionary message of criminal law and sexual morality. South African Journal on Human Rights (in press).

14. Richter ML, Chersich MF, Scorgie F, Luchters S, Temmerman M, Steen R. Sex work and the 2010 FIFA World Cup: time for public health imperatives to prevail. Globalization and Health 2010; 6: 1-6.

15. Rees H, Beksinska ME, Dickson-Tetteh K, Ballard RC, Htun YE. Commercial sex workers in Johannesburg: risk behaviour and HIV status. S Afr J Sci 2000; 96: 283-284.

16. Williams BG, Taljaard D, Campbell CM, et al. Changing patterns of knowledge, reported behaviour and sexually transmitted infections in a South African gold mining community. AIDS 2003; 17(14): 2099-2107.
} 
17. Richter M. Pimp my ride for 2010: Sex work, legal reform and HIV/AIDS. Gender \& Media Diversity Journal 2009; 7: 80-88

18. Loff B, Gaze B, Fairley C. Prostitution, public health, and human-rights law. Lancet 2000; 356: 1764
19. Richter M, Massawe D. A report on the consultation on HIV/AIDS, sex work and the 2010 Soccer World Cup - human rights, public health, soccer and beyond. South African National A Court holel, Cape Town, $26-27$ November 2009. http// www sweto consult $\% 20$ meet $\% 20$ report $\% 20$ web\%20singles2.pdf (accessed 10 March 2010).

\section{Rugby and cervical spine injuries}

At the time of writing, a Cape newspaper reported on a 21-year-old rugby player who died on the field following a presumed spine injury. This highlights the ongoing concerns regarding safety in this contact sport. Although the physicality of rugby is a large part of its attraction, both to spectators and players, no one wishes serious harm.

Two papers in this issue of $S A M J$ review rugby-related injuries to the spine and spinal cord.

Hermanus et al. ${ }^{1}$ provide a 27 -year epidemiological review of the national occurrence of rugby-related spinal cord injuries (SCIs). Under the guidance of Professor Noakes of the Sports Science Institute, the authors identified 264 SCIs. Sadly, 25\% of these patients had died since sustaining the injury. Data were collected on 183 patients (including 30 deceased).

Dunn $e t$ al. ${ }^{2}$ looked at the issue from the perspective of a Western Cape regional acute spine injury unit, reviewing 27 admissions over a 5-year period. This cohort had spinal column injuries, with 6 of the cohort presenting with normal neurological function but mechanical instability requiring stabilisation.

The Hermanus study found an increasing number of injuries up to 2005, with a slight reduction to 12 in 2007. This in contrast to the New Zealand experience of reduced annual injury rates over the past few years. ${ }^{3}$ Dunn et al. found that the Western Cape injury incidence was reduced compared with that in reports from the 1980s, with a current injury rate of 5.4 per annum and a catastrophic injury rate of 1.8 per annum. Of course, any spine injury is one too many.

Both studies found the tackle to be the commonest phase of play in which injury is sustained. This may well be due to recent rule changes reducing scrums by as much as $40 \%$ per game.

Hermanus et al. found a higher incidence of injuries in forwards, with Dunn et al. reporting equal rates in forwards versus the backline. This may well be attributable to the periods reviewed, with the changing game and increasing tackling injury risk increasing backline injuries in the latter years.

The high rate of hooker injuries $30 \%$ in the Hermanus study) confirms the long-held view in terms of risk in this playing position, yet in the recent 5-year period this is no longer the case in the Western Cape, as hookers only account for $11 \%$ of the injuries and scrumhalves and props lead the injury table.

Dunn et al. identified games played outside the metropole as high risk. It is postulated that this represents more poorly controlled games, with immature players playing in higher leagues because of small numbers in the clubs. Hermanus et al. note that there is a demographic bias to access to medical resources and subsequent outcome. Concerns regarding foul play are also raised, with $30 \%$ of injuries occurring as a result of this.

Access to appropriate medical care is a problem highlighted in both papers. Hermanus et al. state that on-site medical personnel were only available in $50 \%$ of cases, with the injured player not being appropriately immobilised in a third of cases. The first medical contact point was frequently inadequate, requiring transfer. This correlated with poorer outcomes.

The vast majority of spinal injuries were dislocations. Dunn et al. followed their cohort up in terms of neurological outcome. None of the ASIA As (complete motor and sensory function) on admission recovered. In contrast to this, 2 of the Bs (sensory preservation) improved to normal. This finding highlights the importance of early recognition of any neurological preservation and appropriate intervention. All the Ds (minor impairment) improved to normal and no surviving patient deteriorated neurologically.

Both studies highlight the difficulty in providing an injury incidence, as surprisingly the number of players/games is not known. Hermanus et al. make a plea to establish a prospective injury register.

Dunn et al. note that only a few injured players (19\%) considered SCI a possibility before injury, and that despite their predicament $60 \%$ would still recommend that their sons play the game. This highlights the strong commitment to the game and the need to make it safer.

Both these studies have provided the impetus for SA Rugby to embark on a proactive educational programme. BokSmart is educating all role players in an effort to minimise injury and promote safe play.

\section{Robert Neil Dunn}

Department of Orthopaedic Surgery University of Cape Town

Corresponding author: R N Dunn (robdunn@mweb.co.za)

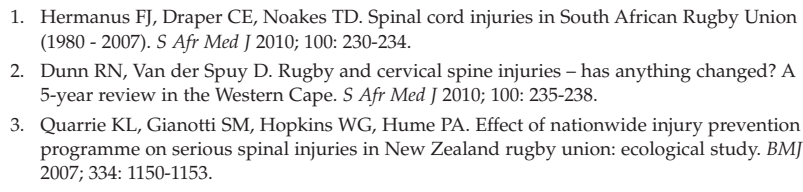

3. Quarrie KL, Gianotti SM, Hopkins WG, Hume PA. Effect of nationwide injury prevention programme on serious spinal injuries in New Zealand rugby union: ecological study. $B M$ 2007; 334: 1150-1153. 